\title{
Determination of Serum Vascular Endothelial Growth Factor Levels in Attention Deficit Hyperactivity Disorder: A Case Control Study
}

\author{
Yasemin Taş Torun', Esra Güney ${ }^{2}$, Arzu Aral ${ }^{3}$, Dicle Büyüktaşkin², Hüseyin Tunca ${ }^{4}$, Yasemen Işik Taner², Elvan işeri ${ }^{2}$ \\ ${ }^{1}$ Child and Adolescent Psychiatry Department, Gulhane Education and Training Hospital, ${ }^{2}$ Child and Adolescent Psychiatry Department, \\ ${ }^{3}$ Department of Immunology, Gazi University Medical Faculty, Ankara, ${ }^{4}$ Child and Adolescent Psychiatry Department, Diyarbakır Education \\ and Training Hospital, Diyarbakır, Turkey
}

\begin{abstract}
Objective: The effect of vascular endothelial growth factor (VEGF) on neuronal development is known, but its relationship with attention deficit hyperactivity disorder (ADHD), a neurodevelopmental disorder, has not yet been fully elucidated. To our knowledge, this is the first human study investigating serum VEGF levels in ADHD patients. In this study, it has been aimed to compare serum VEGF levels between a healthy control group and in ADHD patients to help determine the association between serum VEGF levels and ADHD.

Methods: This study sample included forty-four patients diagnosed with ADHD and 43 healthy volunteer controls between 7 to 14 years old. Blood samples were taken from patients and the healthy control group to assess their serum VEGF levels. VEGF levels were calculated by subjecting the optical densities of the samples to concentrations of known standards as provided in the ELISA kit and then performing a regression correlation analysis.

Results: The mean VEGF level of the children was $333.6 \pm 209.8$ in the ADHD group and $341.3 \pm 201.8$ in the control group. There were no statistically significant differences in serum VEGF levels between the ADHD and control groups $(U=926.000, \mathrm{z}=-0.170, p=0.865)$.

Conclusion: There was no significant difference in serum VEGF levels for untreated ADHD cases and a healthy control group. This is the first human study investigating serum VEGF levels in ADHD patients, so there is a need to replicate these findings.
\end{abstract}

KEY WORDS: Attention deficit hyperactivity disorder; Vascular endothelial growth factor; Children.

\section{INTRODUCTION}

Attention deficit hyperactivity disorder (ADHD) is a persistent neurodevelopmental disorder characterized by inattention, hyperactivity, and impulsivity that affects 5.29\% of children and adolescents and $2.5 \%$ of adults worldwide $[1,2]$. Although biochemical, genetic, psychological and environmental factors are considered part of the etiology of $A D H D$, recent studies have investigated the relationship between ADHD and neurotrophic factors in children and adults [3]. Neurotrophins (NTs) belong to a fam-

Received: January 31, 2019/ Revised: April 15, 2019

Accepted: June 19, 2019

Address for correspondence: Yasemin Taş Torun

Child and Adolescent Psychiatry Department, Gulhane Education and Training Hospital, Emrah, Gen. Dr. Tevfik Sağlam Cd No:11

D:No:11, Keçiören/Ankara 06010, Turkey

E-mail: ysmn.ts@gmail.com

ORCID: https://orcid.org/0000-0002-4922-7594 ily of molecules that regulate the development, maintenance, function, and programmed cell death of neurons. In mammals, NTs are made up of four types: nerve growth factor, brain-derived neurotrophic factor (BDNF), NT-3, and NT-4. In addition, we know that some growth factors (GFs) play key roles in neuronal development and neuronal survey $[4,5]$. During neural development, myriad biological events like neurogenesis, gliogenesis, cellular migration, cell differentiation, and synapse formation occur simultaneously. These neurobiological processes are orchestrated by several GFs and help shape the postnatal brain $[5,6]$. GFs have been extensively studied in the postnatal brain, and most of them share similar cell functions to those reported in neurodevelopment $[5,7,8]$. Vascular endothelial growth factors (VEGF) are a major angiogenic GF and have an important role during embriogenesis and pre- and post-natal brain development [9].

(ㄷ) This is an Open-Access article distributed under the terms of the Creative Commons Attribution Non-Commercial License (http://creativecommons.org/licenses/by-nc/4.0) which permits unrestricted non-commercial use, distribution, and reproduction in any medium, provided the original work is properly cited. 
VEGF activity is particularly critical in the brain during development and repair. Severe reductions in VEGF concentrations lead to hypoxia and, subsequently, to degeneration of the cerebral cortex and neonatal death [10-12] . Recently, several neurotrophic factors, particularly BDNF, have been shown to be important in the etiology of ADHD $[4,13-15]$. The effect of VEGF on neuronal development is known, but its relationship with ADHD, a neurodevelopmental disorder, has not yet been fully elucidated. There are two animal studies on this relationship in the literature. These studies found downregulation of VEGF, VEGF receptor (VEGFR)-1 (Flt-1), and VEGFR-2 (Flk-1) receptors, phosphorylated Akt (pAkt) and endothelial nitric oxide synthase (eNOS) in the frontal cortices of stroke-prone, spontaneously hypertensive rats. Since alterations in VEGF signaling are associated with the degeneration of the cerebral cortex, it is possible that these alterations are also implicated in the cerebral abnormalities of patients with ADHD $[9,16]$. Even though volumetric abnormalities in regional cerebral blood flow (CBF) are common in ADHD patients, no study to date has investigated mechanism(s) or factors likely to underlie this phenomenon [17]. But, it has been shown that CBF modulated by the levels of an important central nervous system (CNS) angiogenic factor, VEGF, its key signaling machinery (VEGF, KDR, Flt-1, pAkt, eNOS) in the frontocortical region of animal ADHD models [16].

One human study, evaluating the relationship between systemic inflammation and attention problems assessed attention in 2 year olds. It determined that top-quartile concentrations of interleukin (IL)- 6 receptor, tumor necrosis factor- $\alpha$, IL-8, VEGF, VEFGR1, and VEGFR2 on multiple days were associated with an increased risk of ADHD symptoms [18].

Although the role of VEGF in ADHD neurobiology is not fully understood, a role has been shown for VEGF in other mental disorders, especially major depressive disorder [19]. In recent years the neurovascular dysfunction associated with VEGF has been explored in neurodevelopmental disorders including autism, schizophrenia, and mood disorders. These disorders are correlated with hypoxic conditions during early life and are strongly associated with cognitive dysfunction $[20,21]$. Autism is the most investigated neurodevelopmental disorder in the literature. Studies investigating VEGF levels of patients with autism has been showed that decreased levels of four cytokines (IL-1 $\beta$, IL-8, macrophage inflammatory protein- $1 \beta$, and VEGF) were associated with increased severity of presentation in females only [22]. But another study has been determined that plasma VEGF has no causative or compensatory contribution to the pathology of this disorder [23].

Besides the key role of VEGF in vasculogenesis and vascular function, it is also involved in neuroprotection, neuronal survival, and axonal outgrowth in the CNS. It is thought to have a role in the pathogenesis of psychiatric disorders. The results of a study that investigated the role of VEGF in autism shows an association between serum VEGF levels and autism, suggesting a potential role for angiogenic factors in this neurodevelopmental disorder [24]. Also the studies that have investigated associations between serum VEGF levels and schizophrenia have also been inconsistent [24-29].

In this study, we aimed to compare serum VEGF levels between a healthy control group and in ADHD patients to help determine the association between serum VEGF levels and ADHD. We hypothesized that the serum VEGF levels has a potential biomarker of $A D H D$, should be lower in ADHD patient groups than healthy controls. Our hope is to contribute to the development of new strategies for the diagnosis and treatment of ADHD.

\section{METHODS}

\section{Participants}

This study sample included forty-four patients diagnosed with ADHD and 43 healthy volunteer controls from the Gazi University Medical Faculty, Child and Adolescent Psychiatry Department. Study duration was nine months. The patient sample was selected from children and adolescents admitted for care in the Child and Adolescent Psychiatry Department and diagnosed with ADHD according to the Diagnostic and Statistical Manual of Mental Disorders 5th edition (DSM-5) criteria before they began treatment. The control group included children who came to receive counseling in the outpatient clinic and were not diagnosed with any psychopathology. Healthy controls were evaluated with the same exclusion criteria as the ADHD diagnosed patients by child and adolescent psychiatrists. All patients were screened for psychiatric disorders based on DSM-IV criteria using the Schedule for Affective Disorders and Schizophrenia for 
School Aged Children, Present and Lifetime Version (K-SADS-PL) [30]. A Turkish adaptation, validity and reliability of this form was developed by Gökler et al. [31]. Patients with a comorbid psychiatric, neurologic or genetic disorder were excluded, as were patients with a history of chronic systemic diseases, such as endocrine and allergic diseases. Patients who had previously used psychotropic drugs were excluded as well. The control group consisted of healthy children age and sex matched with the participants diagnosed with ADHD. Written informed consent was obtained from all subjects. This study was approved by the ethics committee of Gazi University (date: 03.07.2017, number: 347).

\section{Serum Samples and Analysis}

Blood samples were taken from patients and the healthy control group to assess their serum VEGF levels. Venous blood samples were collected from an antecubital vein; $10 \mathrm{ml}$ of venous blood from each patient was sampled into biochemistry tubes. The tubes were centrifuged at $2,000 \times g$ for 15 minutes after an incubation period of 30 minutes. Samples were stored frozen at $-80^{\circ} \mathrm{C}$ before analysis [26]. VEGF levels were measured using a commercially available enzyme-linked immunosorbent assay (ELISA) kit (human VEGF-A Platinum ELISA kit; eBioscience, Vienna, Austria; catalog number: BMS277/2 and BMS277/2TEN). The samples were analyzed in a single session without designating whether they were from the control or the patient group. VEGF levels were calculated by subjecting the optical densities of the samples to concentrations of known standards as provided in the ELISA kit and then performing a regression correlation analysis.

\section{Statistical Analysis}

Statistical evaluation of the study was done with the SPSS 17.0 software program (SPSS Inc., Chicago, IL, USA). We used a two tail independent $t$ test to compare the age differences between the control and ADHD groups. In ad- dition, a chi-square test was used to evaluate differences for sex. Serum VEGF levels of individuals had non- normal distribution so the differences between the values of the patient and the control groups were analyzed with a Mann - Whitney $U$ test. Differences were considered significant when $p$ value was less than 0.05 .

\section{RESULTS}

This study included 44 patients diagnosed with ADHD and 43 control subjects. The mean age of the children was $9.14 \pm 1.62$ years in the ADHD group and $8.91 \pm 1.91$ years in the control group. The age range was 7 to 13 for the ADHD group and 7 to 14 for the control group. In the ADHD group, 32 of the patients were male and 12 were female; in the control group, 37 of the participants were male and 6 were female. There were no significant differences between the patient and control groups with respect to age and gender $(p>0.05)$.

The mean VEGF level $(\mathrm{pg} / \mathrm{ml})$ of the children was $333.6 \pm$ 209.8 in the ADHD group and $341.3 \pm 201.8$ in the control group. There were no statistically significant differ-

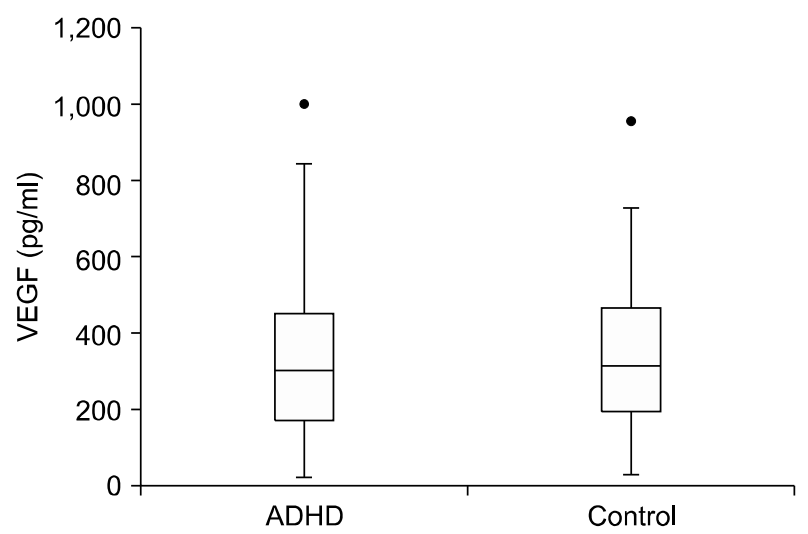

Fig. 1. The distribution of serum VEGF levels $(\mathrm{pg} / \mathrm{ml})$ for the ADHD and control groups.

VEGF, vascular endothelial growth factor; ADHD, attention deficit hyperactivity disorder.

Table 1. The serum VEGF levels of the ADHD and control groups

\begin{tabular}{|c|c|c|c|c|c|c|}
\hline \multirow{2}{*}{ VEGF level } & \multirow{2}{*}{$\operatorname{ADHD}(\mathrm{n}=44)$} & \multirow{2}{*}{ Control $(n=43)$} & \multirow{2}{*}{ Total $(n=87)$} & \multicolumn{2}{|c|}{ Statistics } & \multirow{2}{*}{$p$ value } \\
\hline & & & & U & z & \\
\hline $\begin{array}{l}\text { Mean } \pm \text { standard deviation } \\
\text { Median (minimum }- \text { maximum) }\end{array}$ & $\begin{array}{c}333.6 \pm 209.8 \\
302.1(24.0-1,002.1)\end{array}$ & $\begin{array}{c}341.3 \pm 201.8 \\
313.0(31.2-956.7)\end{array}$ & $\begin{array}{c}337.4 \pm 204.7 \\
311.2(24.0-1,002.1)\end{array}$ & 926.000 & -0.170 & 0.865 \\
\hline
\end{tabular}

VEGF, vascular endothelial growth factor; $A D H D$, attention deficit hyperactivity disorder. 
ences in serum VEGF levels between the ADHD and control groups $(U=926.000, \mathrm{z}=-0.170, p=0.865)$. The serum VEGF levels of the ADHD and control groups are summarized in Table 1 and Figure 1.

\section{DISCUSSION}

This study compared serum VEGF levels of untreated ADHD patients and a healthy control group. Our results showed no significant difference in serum VEGF levels between the ADHD and healthy control groups. To our knowledge, this is the first human study investigating serum VEGF levels in ADHD patients.

Although VEGF levels have been shown to be low in ADHD animal models, serum VEGF levels are similar in children with ADHD and a healthy control group. This may be due to the fact that animal models do not accurately represent human ADHD neurobiology $[9,16]$. In animal models, construct validity depends on the knowledge about the human neurobiology of the modelled disease. The validity of ADHD animal models is based on behavioral similarity because the neurobiology of the disease is not clear. So, construct validity for ADHD animal models is relatively weak [32].

It is also possible that serum VEGF levels in ADHD may not reflect central VEGF levels $[9,16]$. One study with extremely low birth-weight preterm babies found increased VEGF levels in reconstituted newborn blood spots associated with an increased risk of ADHD in the same children at 10 years old. One explanation proposed by those authors for this result was that neurotrophic proteins, including VEGF, may modulate the increased risk of ADHD in conjunction with systemic inflammation [18]. However, in that study VEGF levels were obtained from newborn blood spots and were not replicated at 10 years old. In ADHD, age-related changes in brain blood flow have known and VEGF is an important angiogenic factor for brain blood flow. Thereby, it could also be that VEGF levels, though high in the first month of infancy, reach normal levels in later in pateints with ADHD through compensatory mechanisms in line with CBF [17]. Differences in $\mathrm{CBF}$ at ADHD may be due to other angiogenic factors except VEGF.

The present study has several limitations. First, subgroups of ADHD were not evaluated in this study. Nor was any correlation examined in relation to the severity of clinical symptoms and VEGF levels. Also, this study has small sample size and just cross-sectional study, longitudinal follow-up study with larger sample size is needed to clarify the relations between serum VEGF and ADHD.

At the same time, this study has several strong points. This is the first study quantifying serum concentrations of VEGF in patients with ADHD. None of the ADHD patients included in this study had any history of medication use, nor had they been administered psychostimulants or other psychiatric treatments. Furthermore, the exclusion of comorbid psychiatric and systemic disorders and mental retardation contributes to the reliability of the results of the present study.

In conclusion, there was no significant difference in serum VEGF levels for untreated ADHD cases and a healthy control group. This is the first human study investigating serum VEGF levels in ADHD patients, so there is a need to replicate these findings.

\section{a Conflicts of Interest}

No potential conflict of interest relevant to this article was reported.

\section{Author Contributions}

Conceptualization: Yasemin Taş Torun, Esra Guney. Data acquisition: Yasemin Taş Torun, Esra Guney, Dicle Buyuktaskın, Huseyin Tunca. Formal Analysis: Arzu Aral. Supervision: Yasemen Isık Taner, Elvan Iseri. Review and editting: Yasemin Taş Torun, Esra Guney, Dicle Buyuktaskın, Yasemen Isık Taner, Elvan Iseri.

\section{ORCID}

Yasemin Taş Torun https://orcid.org/0000-0002-4922-7594 Esra Güney https://orcid.org/0000-0002-4043-8301 Arzu Aral https://orcid.org/0000-0002-7300-1624 Dicle Büyüktaşkin https://orcid.org/0000-0003-4679-3846 Hüseyin Tunca https://orcid.org/0000-0002-1227-5330 Yasemen Işik Taner https://orcid.org/0000-0001-8560-5161 Elvan İşeri https://orcid.org/0000-0002-1809-5867

\section{REFERENCES}

1. Polanczyk G, de Lima MS, Horta BL, Biederman J, Rohde LA. The worldwide prevalence of ADHD: a systematic review and metaregression analysis. Am J Psychiatry 2007;164: 942-948.

2. Aguiar A, Eubig PA, Schantz SL. Attention deficit/hyperactivity disorder: a focused overview for children's environmental 
health researchers. Environ Health Perspect 2010; 118:1646-1653.

3. Tsai SJ. Role of neurotrophic factors in attention deficit hyperactivity disorder. Cytokine Growth Factor Rev 2017;34:3541.

4. Syed Z, Dudbridge F, Kent L. An investigation of the neurotrophic factor genes $G D N F, N G F$, and NT3 in susceptibility to ADHD. Am J Med Genet B Neuropsychiatr Genet 2007;144B: 375-378.

5. Galvez-Contreras AY, Campos-Ordonez T, Gonzalez-Castaneda RE, Gonzalez-Perez O. Alterations of growth factors in autism and attention-deficit/hyperactivity disorder. Front Psychiatry 2017;8:126.

6. Costales J, Kolevzon A. The therapeutic potential of insulin-like growth factor- 1 in central nervous system disorders. Neurosci Biobehav Rev 2016;63:207-222.

7. Ribasés M, Ramos-Quiroga JA, Hervás A, Bosch R, Bielsa A, Gastaminza X, et al. Exploration of 19 serotoninergic candidate genes in adults and children with attention-deficit/hyperactivity disorder identifies association for 5HT2A, DDC and MAOB. Mol Psychiatry 2009;14:71-85.

8. Galvez-Contreras AY, Gonzalez-Castaneda RE, Luquin S, Gonzalez-Perez O. Role of fibroblast growth factor receptors in astrocytic stem cells. Curr Signal Transduct Ther 2012;7: 81-86.

9. Jesmin S, Togashi H, Sakuma I, Mowa CN, Ueno K, Yamaguchi $\mathrm{T}$, et al. Gonadal hormones and frontocortical expression of vascular endothelial growth factor in male stroke-prone, spontaneously hypertensive rats, a model for attention-deficithyperactivity disorder. Endocrinology 2004; 145:4330-4343.

10. Virgintino D, Errede M, Robertson D, Girolamo F, Masciandaro A, Bertossi M. VEGF expression is developmentally regulated during human brain angiogenesis. Histochem Cell Biol 2003; 119:227-232.

11. Haigh JJ, Morelli PI, Gerhardt H, Haigh K, Tsien J, Damert A, et al. Cortical and retinal defects caused by dosage-dependent reductions in VEGF-A paracrine signaling. Dev Biol 2003; 262:225-241.

12. Skaper SD. The biology of neurotrophins, signalling pathways, and functional peptide mimetics of neurotrophins and their receptors. CNS Neurol Disord Drug Targets 2008;7:46-62.

13. Kan KJ, Dolan CV, Nivard MG, Middeldorp CM, van Beijsterveldt CE, Willemsen G, et al. Genetic and environmental stability in attention problems across the lifespan: evidence from the Netherlands twin register. I Am Acad Child Adolesc Psychiatry 2013;52:12-25.

14. Castellanos FX, Lee PP, Sharp W, Jeffries NO, Greenstein DK, Clasen LS, et al. Developmental trajectories of brain volume abnormalities in children and adolescents with attention-deficit/hyperactivity disorder. JAMA 2002;288:1740-1748.

15. Liu DY, Shen XM, Yuan FF, Guo OY, Zhong Y, Chen JG, et al. The physiology of BDNF and its relationship with $A D H D$. Mol Neurobiol 2015;52:1467-1476.
16. Jesmin S, Togashi H, Mowa CN, Ueno K, Yamaguchi T, Shibayama A, et al. Characterization of regional cerebral blood flow and expression of angiogenic growth factors in the frontal cortex of juvenile male SHRSP and SHR. Brain Res 2004; 1030:172-182.

17. Oner $\mathrm{O}$, Oner $\mathrm{P}$, Aysev A, Küçük $\mathrm{O}$, Ibis E. Regional cerebral blood flow in children with ADHD: changes with age. Brain Dev 2005;27:279-285.

18. Allred EN, Dammann O, Fichorova RN, Hooper SR, Hunter $\mathrm{SJ}$, Joseph RM, et al. Systemic inflammation during the first postnatal month and the risk of attention deficit hyperactivity disorder characteristics among 10 year-old children born extremely preterm. J Neuroimmune Pharmacol 2017;12:531-543.

19. Clark-Raymond A, Meresh E, Hoppensteadt D, Fareed J, Sinacore J, Garlenski B, et al. Vascular endothelial growth factor: potential predictor of treatment response in major depression. World J Biol Psychiatry 2017; 18:575-585.

20. Howell KR, Armstrong J. Vascular endothelial growth factor (VEGF) in neurodevelopmental disorders. Curr Behav NeurosCi Rep 2017;4:299-308.

21. Newton SS, Fournier NM, Duman RS. Vascular growth factors in neuropsychiatry. Cell Mol Life Sci 2013;70:1739-1752.

22. Masi A, Breen EJ, Alvares GA, Glozier N, Hickie IB, Hunt A, et al. Cytokine levels and associations with symptom severity in male and female children with autism spectrum disorder. Mol Autism 2017;8:63.

23. Zakareia FA, Al-Ayadhi LY, Al-Drees AA. Study of dual angiogenic/neurogenic growth factors among Saudi autistic children and their correlation with the severity of this disorder. Neurosciences (Riyadh) 2012;17:213-218.

24. Emanuele E, Orsi P, Barale F, di Nemi SU, Bertona M, Politi P. Serum levels of vascular endothelial growth factor and its receptors in patients with severe autism. Clin Biochem 2010; 43:317-319.

25. Lee BH, Hong JP, Hwang JA, Ham BJ, Na KS, Kim WJ, et al. Alterations in plasma vascular endothelial growth factor levels in patients with schizophrenia before and after treatment. Psychiatry Res 2015;228:95-99.

26. Pillai A, Howell KR, Ahmed AO, Weinberg D, Allen KM, Bruggemann J, et al. Association of serum VEGF levels with prefrontal cortex volume in schizophrenia. Mol Psychiatry 2016;21:686-692.

27. Fulzele S, Pillai A. Decreased VEGF mRNA expression in the dorsolateral prefrontal cortex of schizophrenia subjects. Schizophr Res 2009;115:372-373.

28. Nguyen TT, Dev SI, Chen G, Liou SC, Martin AS, Irwin MR, et al. Abnormal levels of vascular endothelial biomarkers in schizophrenia. Eur Arch Psychiatry Clin Neurosci 2018;268: 849-860.

29. Misiak B, Stramecki F, Stańczykiewicz B, Frydecka D, Lubeiro A. Vascular endothelial growth factor in patients with schizophrenia: a systematic review and meta-analysis. Prog Neuropsychopharmacol Biol Psychiatry 2018;86:24-29. 
30. Kaufman J, Birmaher B, Brent D, Rao U, Flynn C, Moreci P, et al. Schedule for affective disorders and schizophrenia for school-age children-present and lifetime version (K-SADS-PL): initial reliability and validity data. I Am Acad Child AdolesC Psychiatry 1997;36:980-988.

31. Gökler B, Ünal F, Pehlivantürk B, Kültür EÇ, Akdemir D, Taner Y. [Reliability and validity of schedule for affective disorders and schizophrenia for school age children--present and lifetime version--Turkish version (K-SADS-PL-T)]. Turk J Child Adolesc Ment Health 2004;11:109-116. Turkish.

32. Sontag TA, Tucha O, Walitza S, Lange KW. Animal models of attention deficit/hyperactivity disorder (ADHD): a critical review. Atten Defic Hyperact Disord 2010;2:1-20. 